\title{
Vapor condensation on curvilinear fins with condensate suction from the interfin space
}

\author{
Yuriy Lyulin ${ }^{1,2, a}$, Irina Tueva ${ }^{1,3}$ and Igor Marchuk $k^{1,4}$ \\ ${ }_{1}^{1}$ Institute of Thermophysics, 1, Lavrentiev Ave., 630090, Novosibirsk, Russia \\ ${ }^{2}$ Tomsk Polytechnic University, 30, Lenina Ave, Tomsk, 634050, Russia \\ ${ }^{3}$ Novosibirsk State University, 2, Pirogov Ave., 630090, Novosibirsk, Russia \\ ${ }^{4}$ Novosibirsk State Agrarian University, 160, Dobrolyubov Ave., 630039, Novosibirsk, Russia
}

\begin{abstract}
Vapor condensation of the pure ethanol on the curvilinear fin was studied theoretically. Optimized profile of the fin surface providing maximum condensate flow rate has been calculated. New experimental rig and condenser with the optimized fin profile have been designed and created. Numerical simulation of the average heat transfer coefficient in depends of temperature drop and interfin space has been performed. It was found that the value of the flooding level of the interfin space significantly affects the intensity of condensation as a whole, however, it does not affect significantly the process of condensation on the upper convex part of the fin surface.
\end{abstract}

\section{Introduction}

Vapor condensation on finned surfaces is widely used in technique applications. Numerous experimental studies and theoretical models are presented in the literature. Gregorig [1] first derived a theoretical model for condensation on curvilinear fin with account of surface tension. The fin was described by equation for a spiral with variable direction of rotation. Subsequent models for stationary vapour film condensation on parametric family of curvilinear fins with power dependence of the curvature have been presented in [2-5]. Some experimental results related to the film wise vapour condensation on curvilinear fins are presented in $[6,7]$. Description of various theoretical models and experimental results on film wise condensation are presented in several books and reviews [8-12]. The widespread validation method of the theoretical models is based on comparison between measurement of average heat transfer coefficient and one calculated by the model. But in most articles the flooding of the interfin space are not considered. The flooding of the interfin space in condenser leads to decreasing of intensive condensation area and reduces significantly the intensity of condensation. The problem of removing condensate from the interfin space is particularly important at microgravity conditions. One solution to this problem would be to use suction of the condensate from the interfin grooves.

The main goals of the work are development of a new experimental rig and numerical study of film condensation on the curvilinear fins with the suction of condensate from the interfin space.

\footnotetext{
${ }^{\text {a } C o r r e s p o n d i n g ~ a u t h o r: ~ l y u l i n @ i t p . n s c . r u ~}$
} 


\section{Experimental setup}

For the studies of vapor condensation in the condenser with curvilinear fins a new experimental rig was created, see Fig. 1. The experimental rig consists of the following components: test cell (1); high precision liquid pump (2); evaporator (3); liquid flow meter (4); personal computer (5); temperature and pressure sensors (6); vapor flow controller (7); pressure controller (8); vacuum pump (9); control and data acquisition system (10); heat insulated box (11); heater fan (12); thermostat (13); liquid container (14); valves (15-18). Pure vapor of the working liquid prepared in the evaporator at temperature and pressure maintained. Vapor from the evaporator is supplied to the test cell due to the pressure drop provided by the vacuum pump. The pressure of the test cell is defined by temperature of the condenser. The pressure controller jointly with the vacuum pump is used for the fine adjustment of the pressure. A mass flow controller regulates the vapor flow rate at the inlet of test cell. At the outlet of the test cell the vapor is partially pumped out to avoid accumulating of the nondensables. The test cell with all sensors is placed inside of the thermoinsulating box to avoid the unwanted condensation that may appear inside the sensors and the connecting tubing. The temperature of the air inside the thermoinsulating box is maintained at $1-3 \mathrm{C}^{\circ}$ above the saturation temperate of the working vapor using the heating fan. Since presence any cold part in the experimental rig (except the condenser) can lead to an unwanted condensation. This unwanted condensation may appear inside the sensors and the connecting tubing. As a result the unwanted condensation causes the pressure and the flow fluctuations, which can terminate the experiment. Condenser temperature is maintained by cooling water. The condensed liquid is pumped from the test cell to liquid container using the high precision liquid pump.

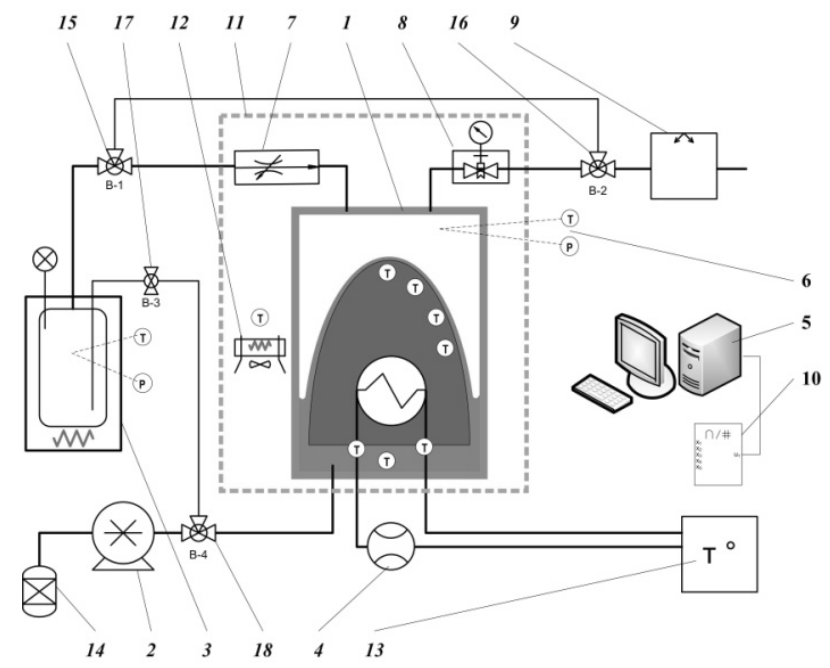

Figure 1. Scheme of the experimental rig.

The most important part of the experimental rig is the test cell. The design and photo of the test cell with a longitudinal fin are shown in Fig. 2. The test cell consists of the condenser in shape of the longitudinal fin, vapor chamber composed of transparent walls and distribution cambers for cooling water. The condenser fin is made of highly thermally conductive material $(\mathrm{Cu})$. Shape of fin for experimental test cell is calculated using the theoretical model and optimized to obtain the maximum condensate flow rate from the fin surface for given geometric parameters. Surface profile of the fin is shown in Fig. 3. The given generatrix curve of the fin surface is a solution of the corresponding variational problem presented in $[4,7]$. The curvature of the generated curve of the fin is defined as a function of curve length $s$ by formula: $\kappa(s)=(a s+b)^{-1 / 2}-c$. The formula constants of defined fin have the following values: $\mathrm{a}=6.769519 \mathrm{e}+000, \mathrm{~b}=4.339554 \mathrm{e}-005, \mathrm{c}=-2.762646 \mathrm{e}+001$, the curvature at the fin top $-1 \mathrm{~mm}^{-1}$, the length of the generatrix curve $S=60 \mathrm{~mm}$. Full rotation of the curve is equal to $90^{\circ}$. The height of the fin is $54 \mathrm{~mm}$, width $30 \mathrm{~mm}$ and length $200 \mathrm{~mm}$. Cooling water from thermostat 
controls the temperature of the condenser. The cooling water is pumping through the distribution chambers and special channels in the fin body with a diameter of $5 \mathrm{~mm}$. The distribution chambers are fitted at the housing face of test cell and have a water temperature measurement. Attachment of the distribution chambers with the condenser is made with the help of two bolts (M8 with $300 \mathrm{~mm}$ length) through housing face walls. Hermeticity of the test cell is achieved by using silicon sealant and rubber seal. The temperature of the condenser is measured with help of six thermocouples $(\mathrm{OD}=0.5 \mathrm{~mm})$ that installed by three pieces on each end of the fin. Thermocouples are installed in the fin body through the front sides and holes with a diameter of $1.5 \mathrm{~mm}$. The implementation depth of the thermocouple tips is $100 \mathrm{~mm}$ and $30 \mathrm{~mm}$ for each side, correspondently. The holes are located on the top, in the middle and at the bottom of the fin at the distance of $5 \mathrm{~mm}$ from the surface of condensation. The housing of the test cell is made of transparent polycarbonate walls. The distance between the side walls and fin surface can be varied in the range of $0.5-1.5 \mathrm{~mm}$. Vapor is supplied into the test cell through a stainless steel tube with inside diameter of $14 \mathrm{~mm}$ and length of $200 \mathrm{~mm}$. The tube is placed at the distance of $20 \mathrm{~mm}$ over the top of the fin. Special holes with diameter of $2 \mathrm{~mm}$ with the step of $10 \mathrm{~mm}$ are located on the side of the tube providing uniform distribution of the vapor inside the test cell. The temperature of the vapor, condensed liquid and cooling water are measured by the thermocouples with diameter of $1.5 \mathrm{~mm}$ that embedded in the test cell using special fitting. Pressure sensor is installed in top cover. Fluid line for pumping out of the condensed liquid is connected from the bottom of test cell.

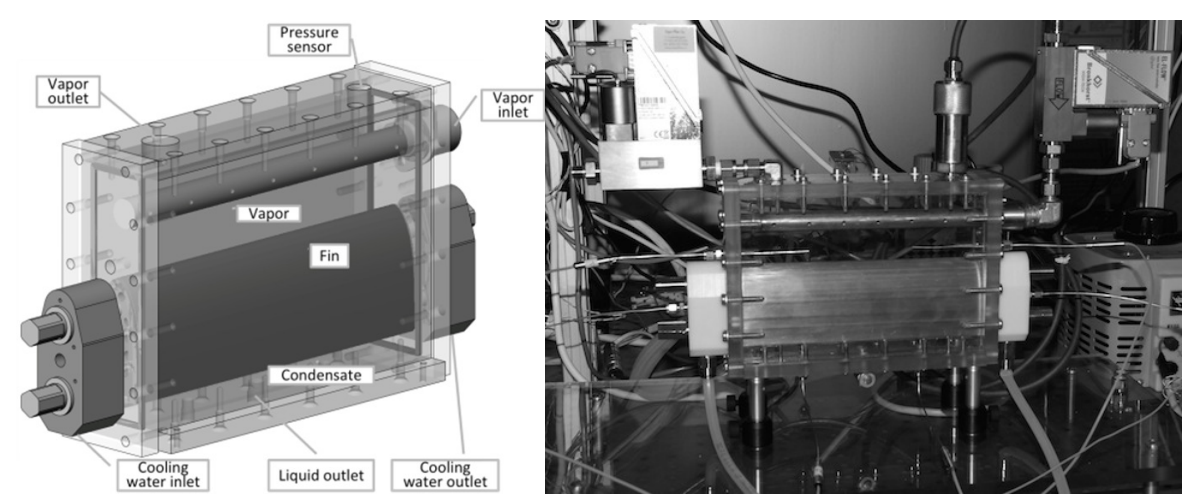

Figure 2. Design and photo of the test cell.

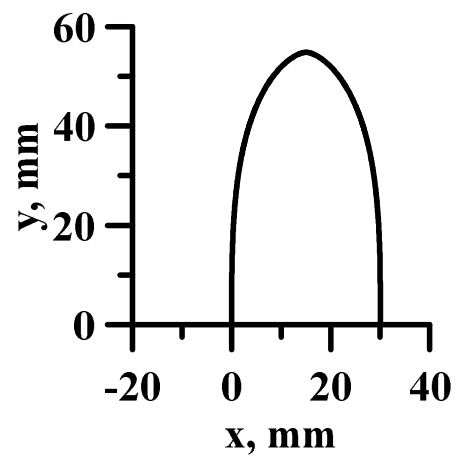

Figure 3. Calculated profile of the fin surface. 


\section{Numerical results}

Numerical calculations of the vapor condensation of pure ethanol on the curvilinear fin have been performed using the theoretical model described in [4,7]. The temperature drop between the surface and vapor temperature varies from $0.2 \mathrm{~K}$ to $10 \mathrm{~K}$. The dependence of the average heat transfer coefficient on the temperature drop for the atmospheric pressure is presented in Fig. 4. The heat transfer coefficients display the usual trend that expected for the condensation of the pure vapor on vertical wall. The heat transfer coefficient is reduced monotonically with the increase of the temperature drop. The values of the average heat transfer coefficient are in the range of $2.6-7.0 \mathrm{~kW} / \mathrm{m}^{2} \mathrm{~K}$, Fig. 4. The distributions of the condensate film thickness for different values of the temperature drop are presented in Fig. 5. The minimum film thickness at top of the fin changes from $1.6 \mu \mathrm{m}$ to $6.9 \mu \mathrm{m}$ for the given temperature range. Dependence of the specific flow rate of condensed liquid along of the fin is shown in Fig. 6. It should be noted that the difference between the curves in Fig 6 is significantly greater than in the Fig 5 . It is explained that the condensate flow rate is proportional to the third power of the condensate film thickness.

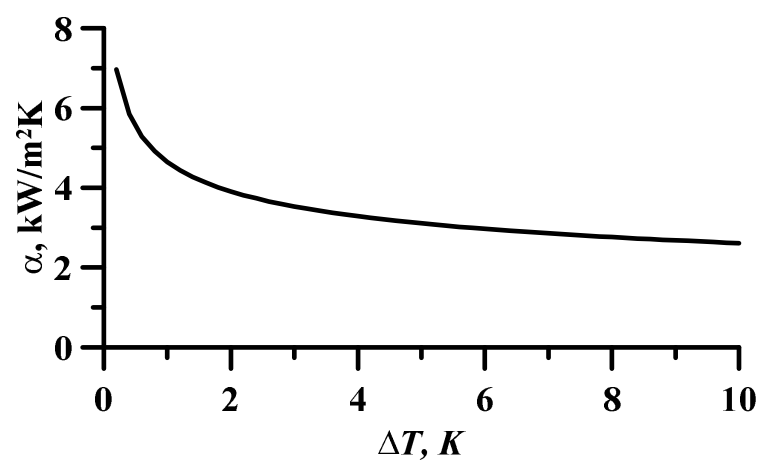

Figure 4. Dependence of the average heat transfer coefficient on the temperature difference.

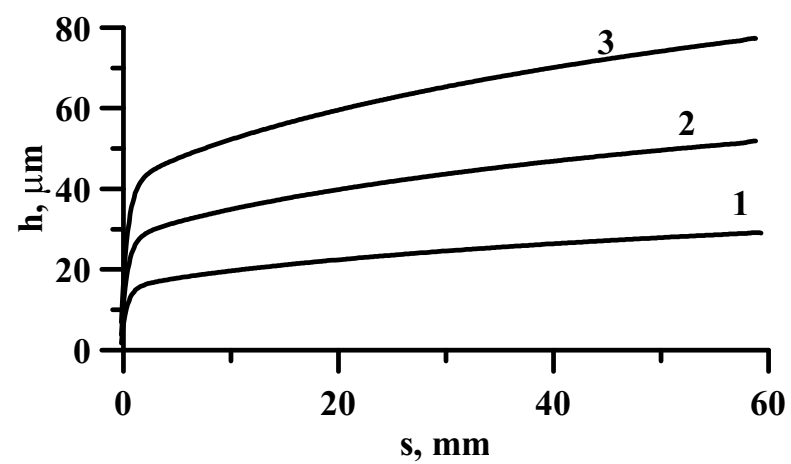

Figure 5. Condensate film thickness along the fin surface. $1-\Delta \mathrm{T}=0.2 \mathrm{~K}, \mathrm{~h}_{\min }=1.6 \mu \mathrm{m}, \alpha=6.97 \mathrm{~kW} / / \mathrm{m}^{2} \mathrm{~K}$; 1 $\Delta \mathrm{T}=2 \mathrm{~K}, \mathrm{~h}_{\min }=3.8 \mu \mathrm{m}, \alpha=3.91 \mathrm{~kW} / \mathrm{m}^{2} \mathrm{~K} ; 1-\Delta \mathrm{T}=10 \mathrm{~K}, \mathrm{~h}_{\min }=6.9 \mu \mathrm{m}, \alpha=2.61 \mathrm{~kW} / / \mathrm{m}^{2} \mathrm{~K}$. 


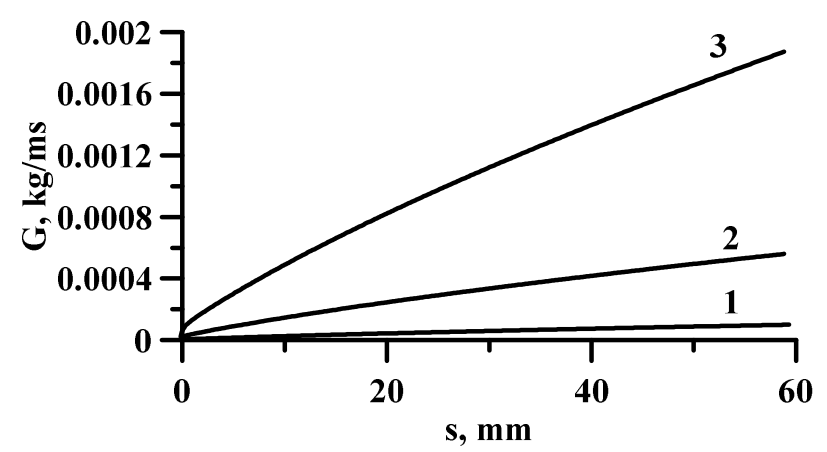

Figure 6. Mass flow rate of the condensate along the fin surface. $1-\Delta T=0.2 \mathrm{~K}, 1-\Delta T=2 \mathrm{~K}, 1-\Delta \mathrm{T}=10 \mathrm{~K}$.

\section{Conclusions}

New experimental rig and numerical calculations for study of film vapor condensation on the curvilinear fins and numerical with the suction of condensate from the interfin space has been performed. Shape of fin for experimental test cell is calculated using the theoretical model and optimized to obtain the maximum condensate flow rate from the fin surface for given geometric parameters. The results of calculations of condensation of ethanol on the fin have been obtained for different values of the temperature difference between saturation temperature and fin surface temperature. The calculated heat transfer coefficient is in the range of $2.6-7.0 \mathrm{~kW} / / \mathrm{m}^{2} \mathrm{~K}$. The value of the flooding level of the interfin grooves significantly affects the intensity of condensation as a whole, however, it does not affect the process of condensation on the upper convex part of the fin surface. For the calculation of operational parameters of the condenser it is possible take into account the total condensate flow only from the convex part of the condenser fins to determine its average performance.

The work was financially supported by the Russian Ministry of Education and Science (project identifier RFMEFI61614X0016).

\section{References}

1. R. Gregorig, Zeitschrift für angewandte Mathematik und Physik Bd. 5, 36 - 49 (1954)

2. C. Zener and A. Lavi, Journal of Heat Transfer 96, 205-209 (1974)

3. T. Adamek, Warme - und Stoffubertragung 15, 255 - 270 (1981)

4. I.V. Marchuk and O.A. Kabov, Encyclopedia of Two-Phase Heat Transfer and Flow II: Special Topics and Applications, 3, 133-176 (2015)

5. I.V. Marchuk and O.A. Kabov, Doklady Physics, 61, 19-23 (2016)

6. A. Glushchuk, I.V. Marchuk and O.A. Kabov, Journal Microgravity Science and Technology 23, 65-74 (2011)

7. I.V. Marchuk, A.V. Gluschuk and O.A. Kabov, Technical Physics Letters 32(5), 388-391 (2006)

8. R.L. Webb, Principles of Enhanced Heat Transfer, 556 (1994)

9. J.R. Thome, Engineering Data Book III (2008)

10. V.G. Rifert, H.F. Smirnov, Condensation Heat Transfer Enhancement, 371 (2004)

11. J. Rose, Enhanced condensation heat transfer, 49 (3), 626-635 (2006)

12. A. Cavallini, G. Censi, D. Del Col, L. Doretti, G.A. Longo, L. Rossetto, C. Zilio, International Journal of Refrigeration 26, 373-392 (2003) 